\title{
AVAliaÇÃo dA VULNERABILIDADE AMBIENTAL DE RESERVATÓRIOS À EUTROFIZAÇÃO
}

\section{EVALUATION OF RESERVOIRS ENVIRONMENTAL VULNERABILITY TO EUTROPHICATION}

\section{MARIA CLÉA BRITO DE FIGUEIREDDO}

Pesquisadora da Embrapa Agroindústria Tropical

\author{
ADUNIAS S. TEIXEIRA
}

Professor do Departamento de Engenharia Agrícola, UFC

\section{Lúcia de Fátima Pereira Araújo}

Consultora da Embrapa Agroindústria Tropical

\author{
MORSYLEIDE FREITAS Rosa \\ Pesquisadora da Embrapa Agroindústria Tropical
}

\section{WALT DisNey PAULINo}

Técnico da Companhia de Gestão dos Recursos Hídricos - COGERH

$$
\text { SUETÔNIO MOTA }
$$

Professor do Departamento de Engenharia Hidráulica e Ambiental, UFC

$$
\text { José CARLOS ARAÚJo }
$$

Departamento de Engenharia Hidráulica e Ambiental, UFC

\section{Recebido: 18/05/06 Aceito: 23/10/07}

\section{RESUMO}

Esse trabalho apresenta uma ferramenta de análise da vulnerabilidade de reservatórios à eutrofização, visando subsidiar ações de controle e remediação desse processo. Foram analisadas três subbacias de açudes - Araras, Edson Queiroz e Jaibaras, da bacia do Acaraú, CE, Brasil. A análise multiatributo usada na definição de indicadores ambientais de vulnerabilidade dos açudes à eutrofização, considerou sua sensibilidade e fatores de pressão nas suas sub-bacias que acarretam o transporte de sedimentos e nutrientes para os reservatórios. Foi utilizado um Sistema de Informações Geográficas (SIG) com a ferramenta álgebra de mapas para manipular dados de uso e ocupação do solo, declividade do terreno e erodibilidade do solo. Foi identificada alta vulnerabilidade à eutrofização nos três açudes pelas susceptibilidades à erosão, alta carga poluidora principalmente pela pecuária extensiva na região e baixa profundidade relativa dos reservatórios.

PALAVRAS-CHAVES: Eutrofização, vulnerabilidade ambiental, SIG, reservatórios, Acaraú

\begin{abstract}
This work presents a tool to analyze the vulnerability of reservoirs to eutrophication, aiming to subsidize control and remediation actions related with this process. It was analyzed the water basins of Araras, Edson Queiroz and Jaibaras reservoirs, located in the Acaraú watershed, Ceará, Brazil. The multi-criteria analyses methodology used, in order to define environmental vulnerability indicators to reservoir eutrophication, considered reservoir sensibility and pressure factors in the water basin responsible for the transport of sediments and nutrients to the reservoir. A Geographic Information System (GIS) with map algebra as major tool was applied to soil use and occupation, declivity and erosion indicators. It was identified high vulnerability to eutrophication in the three mentioned reservoirs because of the waterbasins susceptibility to erosion, high phosphorous load mainly from the extensive cattle raising and low relative depth of the reservoirs.
\end{abstract}

KEYWORDS: Eutrophication, environmental vulnerability, GIS, reservoirs, Acaraú 


\section{INTRODUÇÃO}

A eutrofização das águas significa seu enriquecimento por nutrientes, principalmente nitrogênio e fósforo, levando ao crescimento excessivo das plantas aquáticas, tanto planctônicas quanto aderidas, com conseqüente desequilíbrio do ecossistema aquático e progressiva degeneração da qualidade da água dos corpos lênticos. Um dos principais problemas relacionados à eutrofização é a proliferação de cianobactérias em detrimento de outras espécies aquáticas. Muitos gêneros de cianobactérias quando submetidas a determinadas condiçôes ambientais podem produzir toxinas que chegam a ser fatais aos animais e aos seres humanos.

Em função da eutrofização, muitos reservatórios e lagos no mundo já perderam sua capacidade de abastecimento de populações, de manutenção da vida aquática e de recreação. Um número crescente de trabalhos vem sendo desenvolvido, demonstrando a gravidade do problema (Vollenweider, 1976; McCauley, E. \& Kalff, J., 1981; Arcifa, 1984; Giani et al, 1988; Goodwin, 1997; Pinto-Coelho, \& Araújo, 1997; Pinto-Coelho, 1998; Sendacz \& Kubo, 1999; Pinto-Coelho \& Greco, 1999; Matsumura-Tundisi,1999; Dodson et al, 2000; Aka et al, 2000; Espíndola et al, 2000; Starling, 2000; Boechat, 2000; Masson et al, 2000; Kozlowsky-Suzuki \& Bozelli, 2002; Meschiatti \& Arcifa, 2002; Sampaio et al, 2002; Bennion et al, 2005; Pinto-Coelho et al, 2005). No Ceará, o monitoramento da água de 4 açudes, que são mananciais de abastecimento humano, nas bacias do Curu e Acaraú vem apresentando concentrações elevadas de nitrogênio e fósforo, sendo um fator de preocupação por parte do poder público e das populaçōes usuárias das águas (Araújo et al, 2006).

A ocorrência de processos de eutrofização em inúmeros reservatórios, aliada ao déficit de investimento em infra-estrutura dos serviços de saneamento básico em todo o país, dificulta a tomada de decisão pelo poder público de quais reservatórios encontram-se em situação mais crítica para implementação de açôes emergenciais de controle e reversão desse processo. Em países como Estados Unidos e Inglaterra, esse problema vem sendo abordado em trabalhos que buscam ajudar a to- mada de decisão a partir do estudo da vulnerabilidade das bacias onde estão localizados reservatórios ou lagos com índices de trofia elevados (Bennion et al, 2005).

A vulnerabilidade ou fragilidade ambiental está relacionada com a susceptibilidade de uma área em sofrer danos quando submetida a uma determinada ação, sendo no caso em estudo, à ação do aporte de nutrientes num corpo d'água. Quanto maior a vulnerabilidade da bacia, menor a chance de recuperação do ambiente. Conhecer a vulnerabilidade de uma área a determinados fatores de pressão ambiental auxilia na priorização de investimentos públicos, normalmente escassos, em diferentes regiōes.

Segundo o Painel Intergovernamental de Mudança Climática (IPCC), a vulnerabilidade de uma determinada região está relacionada à natureza dos fatores que pressionam ou promovem mudanças ambientais, ao grau de sensibilidade do meio à mudança e a sua capacidade regenerativa (Metzger et al, 2006). Esse trabalho descreve um sistema de avaliação da vulnerabilidade à eutrofização, considerando indicadores de pressão nas bacias e a sensibilidade dos reservatórios à carga poluente ao qual são atualmente submetidos. A sistemática de avaliação proposta foi aplicada em três açudes localizados na bacia do Acaraú, Ceará.

\section{METODOLOGIA}

O estudo da vulnerabilidade à eutrofização utiliza a metodologia de análise multiatributo segundo Malczewski
(1999), em ambiente de Sistema de Informaçōes Geográfica (SIG). Essa análise é utilizada quando se deseja tomar uma decisão sobre um determinado problema que possui muitos aspectos ou variáveis a serem consideradas.

A área de interesse corresponde à bacia do rio Acaraú, localizada no oeste do estado do Ceará entre as coordenadas UTM 293676W e 423588W e $9689073 S$ e $9453948 S$. Nessa bacia foram delineadas três sub-bacias cujos exutórios são os açudes Araras, Edson Queiroz e Jaibaras (Figura 1). As áreas das sub-bacias foram definidas tomando-se como base o modelo numérico de terreno da região do Acaraú resultante do levantamento por radar efetuado pela National Aeronautics and Space Administration (NASA) em fevereiro de 2000 em todo o mundo (NASA, 2006). A resolução utilizada pela NASA e adotada nesse trabalho é de $92 \mathrm{~m}$. Na delimitação das subbacias e da rede de drenagem foi aplicada a extensão CRWR-PrePro, segundo Oliveira et al (1999).

A definição de indicadores baseouse na indicação encontrada na literatura das principais causas e formas de mensuração desse processo (Sperling, 1995; Andreoli \& Carneiro, 2005, Chapra, 1997, Jorgensen \& Vollenweider, 2000). Foram utilizados indicadores relacionados aos fatores de pressão e de sensibilidade de reservatórios ao enriquecimento de fósforo para avaliar a vulnerabilidade de reservatórios à eutrofização, conforme Tabela 1.

Cada aspecto foi analisado individualmente e suas variáveis classificadas (hierarquizadas) segundo seu grau de influência nos processos que deter-

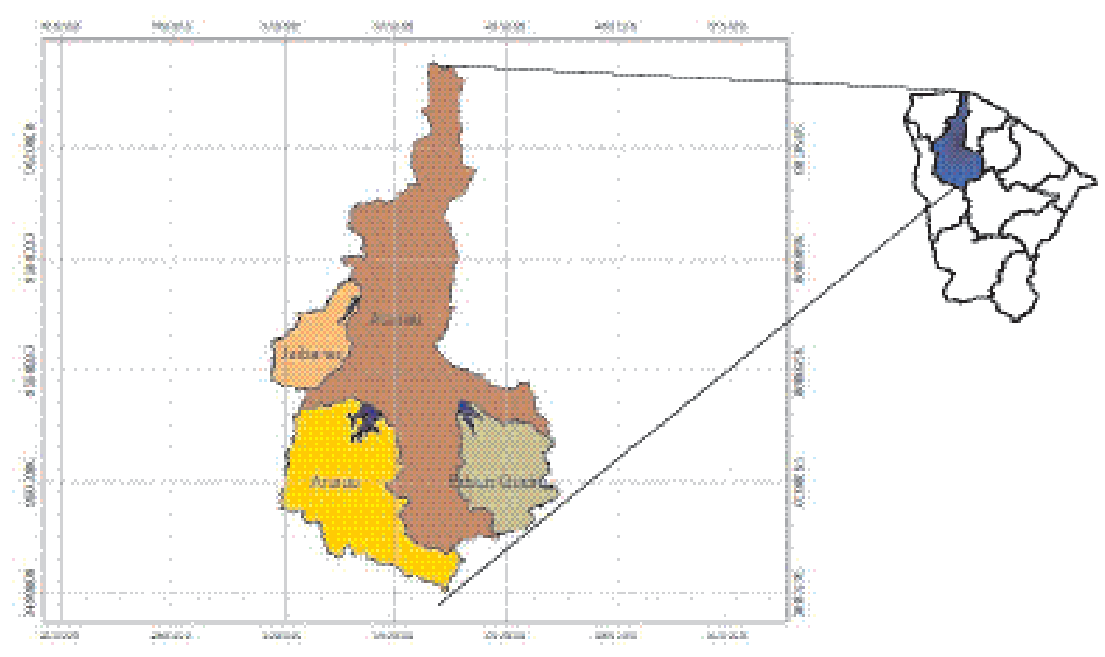

Figura I - Sub-bacias em estudo na bacia do Acaraú 
Tabela I - Indicadores utilizados na análise multiatributo

\begin{tabular}{|c|c|c|}
\hline $\begin{array}{l}\text { Fatores considerados no } \\
\text { estudo da vulnerabilidade }\end{array}$ & Aspecto & Indicador \\
\hline \multirow[t]{4}{*}{ Erosão } & Solo & Erodibilidade do solo \\
\hline & Clima & Intensidade pluviométrica ( $\mathrm{mm} / \mathrm{dia})$ \\
\hline & Uso e ocupação do solo & Exposição do solo \\
\hline & Geomorfologia & Declividade do terreno (\%) \\
\hline Carga poluente & $\begin{array}{l}\text { Carga poluente pontual devido à } \\
\text { urbanização, piscicultura em gaiola } \\
\text { e carga difusa proveniente } \\
\text { da criação de bovinos às margens } \\
\text { dos açudes }\end{array}$ & $\begin{array}{c}\text { Carga de Fósforo Total } \\
\text { (g de } \mathrm{P} / \mathrm{m}^{2} \text { do reservatório . ano) } \\
\text { Profundidade média do reservatório }(\mathrm{m}) \\
\text { Tempo de retenção hidráulica do } \\
\text { reservatório (ano) }\end{array}$ \\
\hline Sensibilidade & Profundidade do reservatório & Profundidade relativa do reservatório (\%) \\
\hline
\end{tabular}

minam a vulnerabilidade ambiental quanto à eutrofização. Os níveis de vulnerabilidade utilizados foram "Baixa", "Média" e "Alta" recebendo os valores 1,2 e 3, respectivamente.

No estudo do fator Erosão para o indicador Erodibilidade do solo, foi utilizado o mapa base de Reconhecimento dos Solos do Ceará elaborado por Jacomine (1973), escala de 1:650.000, contendo as classes de solo do Estado. Utilizando-se o mapa de solos, foi realizada uma classificação da vulnerabilidade das classes de solo à erosão (Tabela 2), conforme Freitas (2003).

Para o cálculo da intensidade pluviométrica, foram utilizados os dados de precipitação de estações pluviométricas localizadas nas bacias do Acaraú com valores diários determinados pela Fundação Cearense de Meteorologia e Recursos Hídricos (FUNCEME) entre os anos de 1974 e 1999. A intensidade pluviométrica é obtida dividindo-se o valor da pluviosidade média anual (mm) pela duração do período chuvoso (meses). Os dados de intensidade pluviométrica foram classificados segundo a escala definida por Crepani, Medeiros \& Palmeira (2004) para o Brasil (Tabela 2).

Foram classificadas imagens do satélite (Araras: CBERS_CCD_ 2_152_105_20051018 e CBERS_ CCD_2_153_105_20051015; Edson Queiroz: CBERS_CCD_2_152_105_ 20051018; Jaibaras: CBERS_CCD_2_ 152_104_20040923, CBERS_CCD_ 2_153_104_20040920 e CBERS_ CCD_2_152_105_20040923.), disponibilizadas pelo Instituto Nacional de Pesquisas Espaciais (INPE), utilizando-se o software ENVI nas seguintes regiōes de interesse: solo exposto, mata densa, mata aberta, água, mata ciliar e área irrigada. As áreas com água foram desconsideradas, assim como as células não classificadas.

As regiōes de interesse utilizadas foram pontuadas (Tabela 2) quanto à vulnerabilidade a processos erosivos, tomando-se como referência o proposta por Ross (2005).

Os mapas de declividade das subbacias foram obtidos a partir do modelo numérico do terreno (NASA, 2000) utilizando-se a extensão "spatial analyst" do Arcview 3.2. As declividades foram classificadas (Tabela 2) tomando como referência Ross (1994).

As cargas de Fósforo Total foram estimadas utilizando-se a seguinte sistemática:

- para a carga proveniente das vilas localizadas até $500 \mathrm{~m}$ do espelho d'água dos açudes, a carga foi obtida a partir do levantamento da população residente, elaborado pela Fundação Nacional de Saúde (FUNASA) de Sobral-CE. Como nessas vilas não existe esgotamento sanitário, considerou-se que cada pessoa gera em média 100L de esgoto bruto por dia (Araújo, 2000), com uma concentração de fósforo de $14 \mathrm{mg} / \mathrm{L}$ (Sperling, 1995);

- para a carga proveniente dos núcleos urbanos inseridos nas bacias, considerou-se a população urbana que não utilizava sistema de fossa, segundo a Pesquisa Nacional de Saneamento Básico do IBGE (2000). Para a carga emitida, foi estimada a carga remanescente que chega ao reservatório após decaimento, considerando a equação de decaimento de primeira ordem, segundo Chapra (1997).

- para a carga proveniente de bovinos, considerou-se que essa carga é em média 9 vezes a carga gerada pelo esgoto bruto humano (BNB, 1998). Essa carga foi calculada apenas para a criação de bois que ocorre às margens do açude. O tamanho do rebanho foi estimado considerando-se a relação entre o total de cabeças de boi e a população na subbacia estudada, de acordo com o censo do IBGE (2000);

- para a carga proveniente da piscicultura, considerou-se que a produção de 1 ton de peixe gera $15 \mathrm{~kg}$ de Fósforo Total (Proença, 2006). A produção total de peixe em gaiola foi obtida em levantamento de campo, junto ao Departamento Nacional de Obras contra as Secas (DNOCs).

Os valores de carga de Fósforo Total foram classificados quanto a vulnerabilidade à eutrofização de acordo com o risco de eutrofização, considerando o gráfico de carga anual por metro quadrado de água versus profundidade média e tempo de retenção hidráulica anual proposto por Vollenweider apud Chapra (1997).

O tempo de retenção hidráulica foi calculado considerando a capacidade máxima do açude dividida pelo aporte anual médio de água, obtido para os anos de 1986 a 2005. O aporte anual médio é calculado como : volume final do açude no ano - volume inicial do açude no ano + evaporação da bacia hidráulica do açude + volume liberado + volume sangrado. As informações sobre capacidade máxima do açude e aporte médio anual foram fornecidas pela Companhia de Gestão dos Recursos Hídricos (COGERH) do Estado do Ceará.

Os açudes foram classificados segundo sua profundidade relativa (Tabela 2), de acordo com Sperling 
(1999). A profundidade máxima foi calculada com base no monitoramento diário dos níveis de água dos respectivos açudes, realizado pelo DNOCS em convênio com a COGERH, desde 1986 nos açudes Araras e Jaibaras e desde 1989 no açude Edson Queiroz.

As áreas dos reservatórios foram obtidas a partir do monitoramento diário dos níveis de água e da interpolação na tabela cota-área-volume dos respectivos açudes. A classificação da vulnerabilidade à eutrofização devido a profundidade relativa do açude observou os critérios estabelecidos por Schafer (1985).

Não foram atribuídos pesos aos indicadores quando da sua agregação, por se considerar que a erosão, a carga pontual de fósforo e a profundidade relativa do reservatório são fatores igualmente importantes num processo de eutrofização. A agregação dos dados de erosão foi realizada utilizando-se a técnica "álgebra de mapas" do geoprocessamento, disponível no Arcview 3.2 com a extensão "spatial analysis". O mapa final de erosão das sub-bacias analisadas consta de áreas com vulnerabilidade alta, média e baixa. Deve-se observar a freqüência de células do grid final para cada classe, sendo a vulnerabilidade à erosão definida como a da classe que possui maior freqüência absoluta de células.

Avaliou-se a vulnerabilidade dos açudes à eutrofização, através da média aritmética dos indicadores profundidade relativa do açude, erosão e carga de fósforo pontual. O resultado da média é um valor que está entre 1 e 3 . Considerando que esse valor deve se enquadrar em uma das três classes de vulnerabilidade (baixa, média ou alta), propõe-se uma repartição linear da escala de 1 a 3 (maior valor - menor valor/3, ou seja, $(3-1) / 3=0,66)$, sendo a vulnerabilidade considerada como baixa para valores entre 1 e 1,66, média para valores entre 1,66 e 2,33 e alta, para valores entre 2,33 e 3 .

\section{RESULTADOS E DISCUSSÃO}

A sub-bacia do açude Araras, detentora da maior área, abrange 15 municípios, inclusive as sedes de Ipu, Ipueiras, Pires Ferreira, Nova Russas, Tamboril e Hidrolândia. A sub-bacia do Edson Queiroz, não abriga sedes municipais, mas parte das zonas rurais principalmente dos municípios de Santa Quitéria e Catunda. A sub-bacia do Jaibaras, a de menor área, abriga as sedes dos municípios de Mucambo, Pacujá e Graça. A Tabela 3 apresenta a área e população de cada sub-bacia.

Nessas sub-bacias predominam os sertôes com topografia plana e levemente ondulada, clima semi-árido e domínio fisiográfico das caatingas. A precipitação média anual na região é de $803,18 \mathrm{~mm}$, referente a 26 anos de monitoramento (1974 e 1999) de sete postos pluviométricos (FUNCEME, 2004). Essa precipitação está concentrada entre os meses de janeiro a julho, tornando-se importante o armazenamento da água acumulada nesses meses para uso durante o resto do ano.

Os açudes Araras, Edson Queiroz e Jaibaras são os três maiores da bacia do Acaraú sendo responsáveis pela perenização do Rio Acaraú. O Araras possui a maior área inundada e capacidade de armazenamento de água (Tabela 4).

Tabela 2 - Classes de vulnerabilidade para cada indicador

\begin{tabular}{|c|c|c|c|c|c|c|}
\hline Vulnerabilidade & Classes de solo & $\begin{array}{c}\text { Fator de } \\
\text { erodibilidade } \\
(\mathrm{k})\end{array}$ & $\begin{array}{c}\text { Intensidade } \\
\text { pluviométrica } \\
(\mathrm{mm} / \mathrm{mês})\end{array}$ & $\begin{array}{l}\text { Classes } \\
\text { de uso } \\
\text { da terra }\end{array}$ & $\begin{array}{c}\text { Classes } \\
\text { de } \\
\text { declividade }\end{array}$ & $\begin{array}{l}\text { Profundidade } \\
\text { relativa } \\
(\mathrm{Zr})\end{array}$ \\
\hline Baixa (1) & $\begin{array}{l}\text { Podzólico } \\
\text { Vermelho-Amarelo, } \\
\text { Planossolo Solódico }\end{array}$ & 0,015 a 0,025 & $<50$ & $\begin{array}{c}\text { Vegetação } \\
\text { densa, mata } \\
\text { ciliar }\end{array}$ & Até 6\% & $\mathrm{Zr}>4 \%$ \\
\hline Média (2) & $\begin{array}{c}\text { Bruno Não-Cálcico, } \\
\text { Litólico, Areia } \\
\text { quartzosa }\end{array}$ & 0,025 a 0,034 & $\geq 50$ e $\leq 525$ & $\begin{array}{c}\text { Vegetação } \\
\text { esparsa }\end{array}$ & $\begin{array}{c}\text { De } \\
6 \text { a } 20 \%\end{array}$ & $4 \% \geq \mathrm{Zr} \geq 2 \%$ \\
\hline Alta (3) & $\begin{array}{l}\text { Podzólico } \\
\text { Vermelho-Amarelo } \\
\text { Eutrófico, Latossolo } \\
\text { Vermelho-Amarelo }\end{array}$ & 0,034 a 0,044 & $>525$ & $\begin{array}{c}\text { Solo } \\
\text { exposto, área } \\
\text { irrigada }\end{array}$ & $\begin{array}{c}\text { Acima de } \\
20 \%\end{array}$ & $\mathrm{Zr}<2 \%$ \\
\hline
\end{tabular}

Tabela 3 - Área e população das sub-bacias em estudo

\begin{tabular}{ccccc}
\hline Subbacia & $\begin{array}{c}\text { Área pertencente } \\
\text { à sub-bacia } \\
\left(\mathrm{Km}^{2}\right)^{*}\end{array}$ & $\begin{array}{c}\text { População urbana } \\
\text { na sub-bacia } \\
(\text { hab)** }\end{array}$ & $\begin{array}{c}\text { População rural } \\
\text { na sub-bacia } \\
(\text { hab)** }\end{array}$ & $\begin{array}{c}\text { Total da } \\
\text { População na } \\
\text { sub-bacia (hab) }\end{array}$ \\
\hline Araras & 3488,364 & 83.359 & 48.294 & 131.653 \\
Edson Queiroz & 1782,503 & -- & 9.814 & 9.814 \\
Jaibaras & 1113,339 & 15.688 & 27.341 & 43.029 \\
\hline
\end{tabular}

* mapa municipal digital fornecido pela COGERH.

** Estimada a partir do Censo do IBGE (2000). 
Tabela 4 - Capacidade dos açudes

\begin{tabular}{ccc}
\hline Açudes & Área inundada $\left(\mathrm{m}^{2}\right)$ & Capacidade $\left(\mathrm{m}^{3}\right)$ \\
\hline Araras & 70.260 .000 & 891.000 .000 \\
Edson Queiroz & 17.710 .000 & 254.000 .000 \\
Ayres de Souza & 11.100 .000 & 104.430 .000 \\
\hline
\end{tabular}

Fonte: Dados fornecidos pela COCERH

O açude Araras, localizado no município de Reriutaba, data de 1958 e barra o Rio Acaraú em seu alto curso, sendo suas águas utilizadas no abastecimento de água dos municípios vizinhos e na irrigação do perímetro Araras Norte. O Edson Queiroz, também conhecido como Serrote, está localizado no município de Santa Quitéria na parte alta da bacia do Acaraú, datando de 1987 o término de sua construção. Represa as água do rio Groaíras, afluente do Rio Acaraú na parte alta da bacia. Atualmente o açude tem como finalidades o controle de enchentes do rio Acaraú, a perenização do rio Acaraú e o abastecimento d'água do município de Santa Quitéria. O Jaibara ou Jaibaras, localizado em Sobral, é o mais antigo entre os estudados, datando de 1936 (DNOCS, 2006). O Jaibaras barra o rio Jaibaras, sendo suas águas utilizadas na irrigação, criação de tilápia em gaiolas e no abastecimento de vários municípios, dentre eles Sobral, o maior município da região.

\section{Resultados da análise de vulnerabilidade das sub- bacias}

Indicadores de erosão

\section{Erodibilidade do Solo}

$\mathrm{Na}$ sub-bacia do Edson Queiroz predominam solos de classe Bruno Não-Cálcico e Litólico, que possuem vulnerabilidade média à erosão $(\mathrm{Ta}$ bela 5). Solos Bruno Não-Cálcico são susceptíveis a erosão devido a coesão e consistência dura do horizonte A e do forte gradiente textural entre os horizontes A e B. Os solos litólicos são pouco espessos, sendo o fluxo d'água em seu interior rapidamente interrompido, facilitando o escoamento superficial (Cunha \& Guerra, 2003).

A sub-bacia do Araras, em sua maior extensão, abriga solos das classes Bruno Não-Cálcico e Podzólico Vermelho-Amarelo Eutrófico (Tabela 5). Segundo Cunha \& Guerra (2003), os solos da classe Podzólico apresentam certa vulnerabilidade à erosão, apesar de sua boa agregação e estruturação, intensificando-se quando ocorrem descontinuidades texturais. Levantamentos de campo realizados por Freitas (2003), mostraram que essa classe de solo possui alta erodibilidade no Ceará.

$\mathrm{Na}$ sub-bacia do Jaibaras predominam solos Litólicos, Podzólicos e Latossolos, com vulnerabilidade média, alta e alta à erosão, respectivamente (Tabela 5). Segundo Freitas (2003), a estrutura física dos Latossolos favorece a erosão.

\section{Intensidade Pluviométrica}

A intensidade pluviométrica é um indicador importante de erosão causada pelas chuvas, uma vez que mede a quantidade de chuva em relação à duração do período chuvoso (Crepani, Medeiros \& Palmeira, 2004). Em todos os pontos da bacia do Acaraú com dados históricos diários de precipitação fornecidos pela FUNCEME (2004), a intensidade pluviométrica é considerada média, de acordo com a classificação adotada (Tabela 6). Nos postos localizadas em Santa Quitéria (sub-bacia do Edson Queiroz), Sobral (próximo a sub-bacia do Jaibaras) e Tamboril (sub-bacia do Araras) a intensidade calculada foi de $422,68,457,50$ e $505,69 \mathrm{~mm} / \mathrm{mês}$, respectivamente.

\section{Declividade}

A maior parte das áreas das subbacias estudadas possui declividades entre 0 e 6\% (Tabela 7), com baixa vulnerabilidade a processos erosivos. A declividade máxima da região foi encontrada na sub-bacia do Jaibaras (51,53\%), na região da Serra Grande.

\section{Uso e ocupação}

A classificação das imagens CBERS2 para a área da sub-bacia do Araras mostra que $54 \%$ da bacia possui baixa vulnerabilidade a erosão, com o solo recoberto por mata ciliar ou vegetação densa de caatinga nos sertóes de Nova Russas, Santa Quitéria e Ipu (Tabela 8). Entretanto, essa sub-bacia possui a maior área de solo exposto (19\%) dentre as três estudadas e é a única que possui área irrigada $\left(2,02 \mathrm{~km}^{2}\right)$ localizada no perímetro irrigado Araras Norte.

A sub-bacia do açude Edson Queiroz possui a maior parte da sua área ocupada por vegetação esparsa, do tipo caatinga arbustiva no sertão de Santa Quitéria, com vulnerabilidade média à erosão (Figura 2). Esse tipo de vegetação deixa o solo exposto grande parte do ano, por perder a folhagem e por ser esparsa, sendo atribuído a essa classe vulnerabilidade média à erosão. A área com solo exposto ocupa $8 \%$ da sub-bacia.

$\mathrm{Na}$ região do Jaibaras, predominam as áreas recobertas com mata ciliar e vegetação densa úmida nas vertentes do planalto da Ibiapaba e da serra da Meruoca (Tabela 8). Essa sub-bacia possui 16\% de sua área com solo exposto, com alta vulnerabilidade à ação das chuvas, que transportam sedimentos para as áreas baixas da sub-bacia, no caso, o açude Jaibaras.

O somatório dos mapas de erodibilidade do solo, intensidade pluviométrica, declividade e uso e ocupação das sub-bacias dos açudes Araras, Edson Queiroz (Figura 3) e Jaibaras indicam que a vulnerabilidade de todas à erosão é "média”, uma vez que os mapas de erosão trazem essa classe como abrangendo o maior número de células do grid (Tabela 9).

Carga de fósforo proveniente de esgoto urbano, piscicultura e bovinocultura

A sub-bacia do açude Araras possui a maior carga de fósforo proveniente da criação de gado bovino nas vilas localizadas às margens do açude (Tabela 10). Nessas vilas habita um total de 13.677 pessoas, sendo estimada a criação extensiva de 4.103 cabeças de gado próximo ao açude. Também contribuem para o aumento de fósforo nas águas represadas, o lançamento de esgoto bruto produzido por 5.816 pessoas que não utilizam fossa e que vivem nas seis sedes municipais inseridas na bacia.

A maior carga de fósforo na subbacia do Edson Queiroz é também proveniente da criação de bois (Tabela 10). A relação entre o número de habitantes e o número de cabeças de gado na sub-bacia é de 1 pessoa para 2 bois. A sub-bacia não possui sedes urbanas em seus limites e tem a menor quanti- 
Tabela 5 - Erodibilidade dos solos encontrados nas sub-bacias em estudo

\begin{tabular}{|c|c|c|c|c|}
\hline Subbacia & Descrição & Área $(\mathrm{km} 2)$ & Vulnerabilidade & Valor \\
\hline \multirow[t]{8}{*}{ Araras } & Açudes e Lagoas & 46,43 & -- & -- \\
\hline & Areias Quartzosas & 55,47 & média & 2 \\
\hline & Bruno Não-Cálcico & 1719,24 & média & 2 \\
\hline & $\begin{array}{l}\text { Latossolo Vermelho- } \\
\text { Amarelo e Vermelho- } \\
\text { escuro }\end{array}$ & 80,64 & Alta & 3 \\
\hline & Planossolo Solódico & 99,87 & Baixa & 1 \\
\hline & $\begin{array}{l}\text { Podzólico Vermelho- } \\
\text { Amarelo Eutrófico }\end{array}$ & 1398,17 & Alta & 3 \\
\hline & Litólicos & 88,54 & Média & 2 \\
\hline & Total & 3488,36 & & \\
\hline \multirow[t]{6}{*}{ Edson Queiroz } & Açudes e Lagoas & 10,64 & -- & -- \\
\hline & Bruno Não Cálcico & 867,29 & Média & 2 \\
\hline & Planossolo Solódico & 315,52 & Baixa & 1 \\
\hline & $\begin{array}{c}\text { Podzólico Vermelho- } \\
\text { Amarelo Eutrófico }\end{array}$ & 154,93 & Alta & 3 \\
\hline & Litólicos & 434,12 & Média & 2 \\
\hline & Total & 1782,50 & & \\
\hline \multirow[t]{7}{*}{ Jaibaras } & Açudes e Lagoas & 14,54 & -- & - \\
\hline & Areias Quartzosas & 46,92 & Média & 2 \\
\hline & Bruno Não Cálcico & 109,78 & Média & 2 \\
\hline & $\begin{array}{l}\text { Latossolo Vermelho- } \\
\text { Amarelo e Vermelho- } \\
\text { escuro }\end{array}$ & 222,71 & Alta & 3 \\
\hline & $\begin{array}{c}\text { Podzólico Vermelho- } \\
\text { Amarelo Eutrófico }\end{array}$ & 294,95 & Alta & 3 \\
\hline & Litólicos & 424,45 & Média & 2 \\
\hline & Total & 1113,34 & & \\
\hline
\end{tabular}

Tabela 6 - Intensidade Pluviométrica

\begin{tabular}{cccccc}
\hline Município & X-coord & Y-coord & $\begin{array}{c}\text { Intensidade } \\
\text { Pluviométrica } \\
(\mathrm{mm} / \mathrm{mês})\end{array}$ & Vulnerabilidade & Valor \\
\hline Sobral & 349718,1455 & 9590585,334 & 457,50 & Média & 2 \\
Santa Quitéria & 369755,7261 & 9520749,264 & 422,68 & Média & 2 \\
Tamboril & 351944,5434 & 9465282,283 & 505,69 & Média & 2 \\
Irauçuba & 413170,4841 & 9587261,016 & 303,37 & Média & 2 \\
Santana do Acaraú & 366416,1293 & 9616068,053 & 462,50 & Média & 2 \\
\hline
\end{tabular}


Tabela 7 - Declividade nas sub-bacias em estudo

\begin{tabular}{ccccccc}
\hline Sub-bacia & Declividade & Vulnerabilidade & Área $\left(\mathrm{Km}^{2}\right)$ & $\%$ da área total & $\begin{array}{c}\text { Declividade } \\
\text { máxima }(\%)\end{array}$ & $\begin{array}{c}\text { Declividade } \\
\text { mínima }(\%)\end{array}$ \\
\hline Araras & $0-6 \%$ & Baixa & 3058,476 & $88 \%$ & & \\
& $6-20 \%$ & Média & 364,759 & $10 \%$ & & 0 \\
Total & $>20 \%$ & Alta & 64,798 & $2 \%$ & & \\
Edson Queiroz & $0-6 \%$ & Baixa & 1415,834 & $79 \%$ & & \\
& $6-20 \%$ & Média & 314,229 & $18 \%$ & & 0 \\
Total & $>20 \%$ & Alta & 52,149 & $3 \%$ & & \\
Jaibaras & $0-6 \%$ & Baixa & 960,984 & $86 \%$ & & \\
& $6-20 \%$ & Média & 118,929 & $11 \%$ & & \\
Total & $>20 \%$ & Alta & 33,194 & $3 \%$ & & \\
\hline
\end{tabular}

Tabela 8 - Classificação do solo

\begin{tabular}{|c|c|c|c|c|}
\hline Sub-bacia & Uso do Solo & Área $\left(\mathrm{km}^{2}\right)$ & $\%$ da área total & Vulnerabilidade \\
\hline \multirow[t]{7}{*}{ Araras } & Água & 77,81 & $2 \%$ & \\
\hline & Vegetação esparsa & 532,06 & $15 \%$ & média \\
\hline & Vegetação densa & 1465,04 & $42 \%$ & baixa \\
\hline & Solo exposto & 654,79 & $19 \%$ & alta \\
\hline & Mata Ciliar & 414,14 & $12 \%$ & baixa \\
\hline & Área irrigada & 2,02 & $0,1 \%$ & alta \\
\hline & área não classificada & 342,51 & $10 \%$ & \\
\hline Total & & 3488,36 & $100 \%$ & \\
\hline \multirow[t]{6}{*}{ Edson Queiroz } & Água & 36,79 & $2 \%$ & \\
\hline & Vegetação esparsa & 1170,50 & $66 \%$ & média \\
\hline & Vegetação densa & 267,02 & $15 \%$ & baixa \\
\hline & Solo exposto & 137,64 & $8 \%$ & alta \\
\hline & Mata Ciliar & 26,89 & $2 \%$ & baixa \\
\hline & área não classificada & 143,65 & $8 \%$ & \\
\hline Total & & 1782,5 & $100 \%$ & \\
\hline \multirow[t]{6}{*}{ Jaibaras } & Água & 22,41 & $2 \%$ & \\
\hline & Vegetação esparsa & 47,37 & $4 \%$ & média \\
\hline & Vegetação densa & 606,01 & $54 \%$ & baixa \\
\hline & Solo exposto & 177,65 & $16 \%$ & alta \\
\hline & Mata Ciliar & 256,86 & $23 \%$ & baixa \\
\hline & área não classificada & 3,05 & $0,3 \%$ & \\
\hline Total & & 1113,34 & $100 \%$ & \\
\hline
\end{tabular}




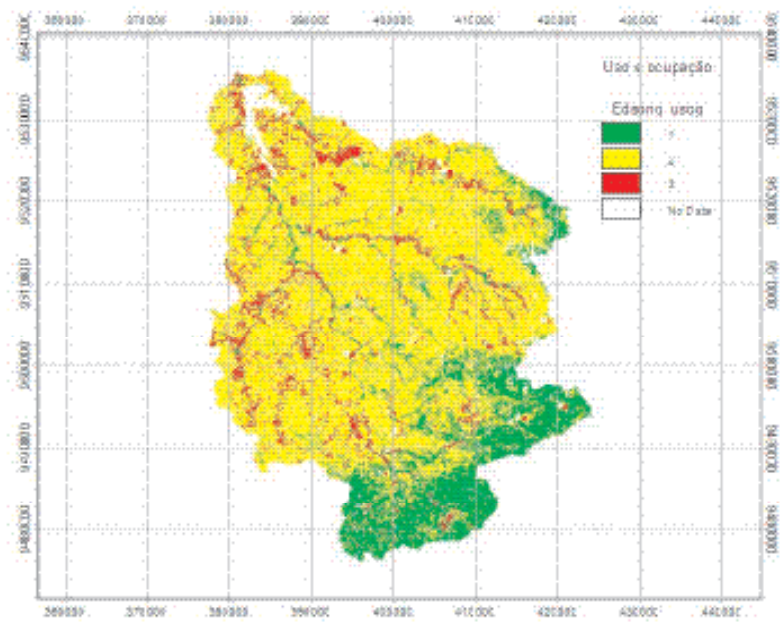

Figura 2 - Vulnerabilidade quanto ao uso e ocupação do solo na subbacia do Edson Queiroz

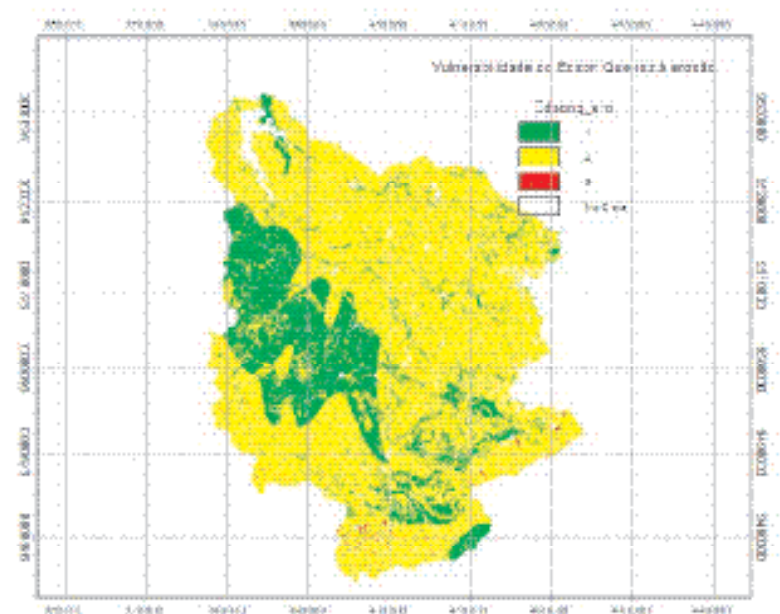

Figura 3 - Vulnerabilidade quanto à erosão no Edson Queiroz

Tabela 9 - Vulnerabilidade das sub-bacias dos açudes à erosão

\begin{tabular}{cccc}
\hline Sub-bacia & Vulnerabilidade & $\begin{array}{c}\text { Frequência absoluta de células } \\
\text { no grid final }\end{array}$ & $\begin{array}{c}\text { Frequência relativa } \\
(\%)\end{array}$ \\
\hline Araras & Baixa & 162832 & 40,64 \\
& Média & 235040 & 58,66 \\
& Alta & 2839 & 0,71 \\
Total & & 400711 & 100,00 \\
Edson Queiroz & Baixa & 41.536 & 22,02 \\
& Média & 146.697 & 77,78 \\
Total & Alta & 375 & 0,20 \\
Jaibaras & & 188.608 & 100,00 \\
& Baixa & 12.469 & 9,73 \\
& Média & 115.497 & 90,10 \\
Total & Alta & 219 & 0,17 \\
\hline
\end{tabular}

Tabela 10 - Carga de fósforo provenientes de fontes pontuais

\begin{tabular}{|c|c|c|c|c|c|c|c|}
\hline Sub-bacia & $\begin{array}{c}\text { Total núcleos } \\
\text { Urbanos } \\
\left(\mathrm{g} / \mathrm{m}^{2} \text {.ano }\right)\end{array}$ & $\begin{array}{c}\text { Total } \\
\text { vilas } \\
\left(\mathrm{g} / \mathrm{m}^{2} \text {.ano }\right) \\
\end{array}$ & $\begin{array}{c}\text { Total } \\
\text { piscicultura } \\
\left(\mathrm{g} / \mathrm{m}^{2} \text {.ano }\right)\end{array}$ & $\begin{array}{c}\text { Total } \\
\text { bovino } \\
\left(\mathrm{g} / \mathrm{m}^{2} \cdot \text { ano }\right) \\
\end{array}$ & $\begin{array}{c}\text { Total } \\
\text { geral } \\
\left(\mathrm{g} / \mathrm{m}^{2} . \text { ano }\right) \\
\end{array}$ & $\begin{array}{c}\text { Profundidade } \\
\text { média/tempo de } \\
\text { retenção (m/ano) }\end{array}$ & Vulnerabilidade \\
\hline Araras & 0,17 & 0,10 & 0,00 & 0,27 & 0,53 & 6,04 & Alta \\
\hline Edson Queiroz & 0,00 & 0,05 & 0,00 & 0,83 & 0,88 & 2,82 & Alta \\
\hline Jaibaras & 0,03 & 0,22 & 0,66 & 0,86 & 1,77 & 3,61 & Alta \\
\hline
\end{tabular}


dade de habitantes (1.595) vivendo nas proximidades do açude.

A criação de boi também é a principal fonte de fósforo na sub-bacia do Jaibaras (Tabela 10). Entretanto, no Jaibaras é praticada a criação de tilápia em gaiolas, que contribui para o aumento dessa carga, assim como o lançamento de esgoto bruto proveniente de 4.819 pessoas que moram às margens do açude e de 1.138 pessoas que não utilizam fossa e que vivem nas sedes dos municípios de Mucambo, Pacujá e Graça.

O tempo médio de retenção hidráulica encontrado para todos os açudes foi elevado (Tabela 11), chegando a 3 anos no Edson Queiroz. Tempos de retenção elevados contribuem para o processo de eutrofização, uma vez que o fitoplâncton disporá de um tempo maior para utilização do fósforo.

Confrontando a carga total pontual de fósforo obtida com o a profundidade média e tempo de retenção hidráulica de cada açude (Vollenweider apud Chapra, 1997), encontra-se uma situação de alta vulnerabilidade à carga de fósforo proveniente das fontes pontuais analisadas em todos os reservatórios (Tabela 10). vatórios

Profundidade Relativa dos reser-

O cálculo da profundidade relativa dos açudes Araras, Edson Queiroz e Jaibaras, de acordo com Schafer (1985), mostra que todos possuem profundidade pequena (Tabela 12) com um epilímio maior, estando mais vulneráveis à eutrofização.

Realizando-se o somatório das vulnerabilidades quanto à erosão, à carga de fósforo e à profundidade relativa do açude, obtém-se a vulnerabilidade do reservatório à eutrofização. Os açudes Araras, Edson Queiroz e Jaibaras apresentam alta vulnerabilidade ambiental a esse processo.

O monitoramento trimestral em cinco pontos da bacia hidráulica dos açudes em estudo, no período setembro/2004 a novembro/2005, apresentou valores médios anuais de fósforo total de $364,24 \mathrm{mg} / \mathrm{m}^{3}$ para o Araras, $457,42 \mathrm{mg} / \mathrm{m}^{3}$ para o Edson Queiroz e $329,12 \mathrm{mg} / \mathrm{m}^{3}$ para o Jaibaras. Esses valores, embora não calculados para regiōes semi-áridas, indicam hipertrofia em todos eles segundo Sperling (1995), o que corrobora com a avaliação de vulnerabilidade à eutrofização realizada nesse trabalho.

Tabela I I - Tempo de retenção hidráulica dos açudes em estudo

\begin{tabular}{cccc}
\hline Açude & $\begin{array}{c}\text { Capacidade } \\
\text { máxima }\left(\mathrm{m}^{3}\right)^{*}\end{array}$ & $\begin{array}{c}\text { Aporte anual } \\
\text { médio }\left(\mathrm{m}^{3}\right)^{*}\end{array}$ & $\begin{array}{c}\text { Tempo de } \\
\text { retenção (ano) }\end{array}$ \\
\hline Araras & $891.000 .000,00$ & $88.121 .768,00$ & 1,43 \\
Edson Queiroz & $254.000 .000,00$ & $18.748 .309,00$ & 3,12 \\
Jaibaras & $104.430 .000,00$ & $20.248 .298,00$ & 0,22 \\
\hline Fonte: * Dados fornecidos pela COGERH
\end{tabular}

Tabela 12 - Profundidade relativa dos açudes em estudo

\begin{tabular}{ccccc}
\hline Açudes & $\begin{array}{c}\text { Área } \\
\text { inundada }\left(\mathrm{m}^{2}\right)\end{array}$ & $\begin{array}{c}\text { Profundidade } \\
\text { relativa (\%) }\end{array}$ & Vulnerabilidade & Valor \\
\hline Araras & 70.260 .000 & 0,31 & alta & 3 \\
Edson Queiroz & 17.710 .000 & 0,45 & alta & 3 \\
Jaibaras & 11.100 .000 & 0,52 & alta & 3 \\
\hline
\end{tabular}

O parâmetro nitrogênio amoniacal total apresentou valores médios anuais de $411,00 \mathrm{mg} / \mathrm{m}^{3}$ para o Araras, $310,70 \mathrm{mg} / \mathrm{m}^{3}$ para o Edson Queiroz e $400,00 \mathrm{mg} / \mathrm{m}^{3}$ para o Jaibaras com pH médio de 8,5, 8,7 e 7,7 respectivamente.

Foi realizada ainda uma investigação quantitativa de fitoplâncton nas águas dos três reservatórios, o que identificou uma densidade média de cianobactérias da ordem de 340127; 381754 e 17935 células/mL no Araras, Edson Queiroz e Jaibaras, respectivamente. Observando-se que os menores valores encontrados para o Jaibaras podem estar associados ao menor tempo de detenção hidráulica do reservatório.

\section{CONCLUSÕES}

A urbanização, a agropecuária e o desmatamento aumentam a carga de nutrientes nos reservatórios, contribuindo para uma maior ocorrência do processo de eutrofização em mananciais. A ferramenta de análise da vulnerabilidade ambiental de reservatórios à eutrofização apresentada nesse trabalho auxilia no processo de tomada de decisão das regiôes mais críticas, onde devem ser adotadas açôes de remediação desse problema. Os indicadores selecionados relativos à sensibilidade dos reservatórios à eutrofização - tempo de retenção hidráulica e profundidade relativa do reservatório - são de amplo conhecimento das organizações gerenciadoras de recursos hídricos. Os indicadores de pressão sobre os açudes -- erosão e carga pontual de fósforo - podem ser obtidos a partir de bases de dados disponíveis ao público, como o censo demográfico do IBGE, mapas de solo estaduais e municipais de Secretarias de Agricultura e Planejamento, imagens do satélite CBERS do INPE, precipitação diária, da FUNCEME, e modelo numérico do terreno, da NASA.

A aplicação dessa ferramenta em três sub-bacias cujos exutórios são açudes que abastecem vários municípios da região do Acaraú apontou alta vulnerabilidade dos três reservatórios, devido à baixa profundidade relativa dos açudes, média propensão à erosão e alta susceptibilidade ao lançamento de cargas de fósforo provenientes do esgoto urbano e das vilas ribeirinhas, da criação de bois nas margens dos açudes e de peixes em gaiolas. Não foi possível priorizar uma das três sub-bacias devido ao fato de todas apresentarem valores críticos quanto aos indicadores utilizados. Esse resultado é preocupante, uma vez que os referidos reservatórios são fontes de abastecimento para as populaçôes residentes na região, devendo ser priorizadas ações de reflorestamento, saneamento e educação ambiental nessas áreas.

Os resultados obtidos são coerentes com os altos valores de fósforo total encontrados nos reservatórios em estudo, indicando congruência e qualidade da metodologia proposta. A ferramenta descrita não utilizou indicadores relacionados ao lançamento de esgoto industrial rico em nutrientes. Uma ampliação dos indicadores deverá integrar análises futuras. Outro aspecto a ser investigado é a ampliação da escala de classificação, incorporando níveis intermediários de vulnerabilidade de forma a tornar a ferramenta mais sensível aos indicadores ambientais. 


\section{REFERÊNCIAS}

AKA, M. et al. Zooplankton variability in 49 shallow tropical reservoirs of Ivory Coast (West Africa). International Review of Hydrobiology, 85: 491-504, 2000.

ANDREOLI, C. \& CARNEIRO, C. Gestão Integrada de Mananciais de Abastecimento Eutrofizados. Curitiba: Sanepar, 2005.

ARAUJO, L. et al. Nutrientes e grau de trofia dos principais reservatórios da bacia hidrográfica do Acaraú-CE-BR. In: VIII SIMPÓSIO ÍTALO BRASILEIRO DE ENGENHARIA SANITÁRIA E AMBIENTAL, CD-ROM. Fortaleza. 2006.

ARAÚJO, L.F.P. et al. Diagnóstico da Qualidade da Água em Seções de Rios da Bacia do Acaraú-CE. In: $3^{\circ}$ CONGRESSO BRASILEIRO DE MEIO AMBIENTE, ANAIS, Salvador, BA, 2004.

ARAÚJO, L. F. P. Reúso com lagoas de estabilização: potencialidade do Ceará. Fortaleza: SEMACE, 2000 .

ARCIFA, M. S. Zooplankton composition of ten reservoirs in Southern Brazil. Hydrobiology, 113 137-145, 1984.

BANCO DO NORDESTE. Manual do Produtor Rural. Fortaleza: BN, 1998.

BENNION, H.et al. The use of a GIS-based inventory to provide a national assessment of standing waters at risk from eutrophication in Great Britain. Science and the Total Environment, v. 344, p. $259-273.2005$.

BOECHAT, I. G. Modificações na composição bioquimica do seston no reservatório da Pampulha $M G$, ao longo de ciclos nictemerais, com ênfase na comunidade fitoplanctônica. Dissertação de Mestrado, Universidade Federal de Minas Gerais, Belo Horizonte, 96p. 2000.

CHAPRA, S. C. Surface Water Quality Modeling. Nova York: McGraw-Hill, 1997.

CREPANI, E.; MEDEIROS, J. S. \& PALMEIRA, A. F. Intensidade pluviométrica: uma maneira de tratar dados pluviométricos para análise da vulnerabilidade de paisagens à perda de solo. INPE-11237RPQ/760. São José dos Campos: Inpe. 2004.

CUNHA, S. B. \& GUERRA, A. J. T. Geomor fologia do Brasil. Rio de Janeiro: Bertrand Brasil, $3^{\mathrm{a}}$ ed. 2003.

DNOCS. Açude Araras. Disponível em: www. dnocs.gov.br. Acesso em 11/01/2006.

DNOCS. Açude Edson Queiroz. Disponível em: www.dnocs.gov.br. Acesso em 11/01/2006.

DNOCS. Açude Jaibaras. Disponível em: www. dnocs.gov.br. Acesso em 11/01/2006.

DODSON, S. I., ARNOTT, S. E. \& COTTINGHAM, K. L. The relationship in lake communities between primary productivity and species richness. Ecology, v. 81, p. 2662-2679. 2000.

ESPÍNDOLA, E. L. G. et al. Spatial heterogeneity of the Tucurui reservoir (State of Pará, Amazonia, Brazil) and the distribution of zooplanktonic species. Rev. Bras. Biol., v. 60, p. 179-194 [ SciELO ].2000.

FREITAS, J. C. A. Mapeamento da erodibilidade do Ceará a partir de mapas pedológicos. Monografia de graduação em Engenharia Civil. Fortaleza: UFC, 2003.

FUNCEME. Planilha de dados pluviométricos do Estado do Ceará para o periodo:1974 a 1999. Fortaleza: FUNCEME. Planilha eletrônica: Excell. 2004

GIANI, A. et al. Ciclo sazonal de parâmetros físico-químicos da água e distribuição horizontal de nitrogênio e fósforo no reservatório da Pampulha (Belo Horizonte, MG, Brasil). Ciência e Cultura, 40, p. 69-77. 1998.

GOODWIN, K. L. Dinâmica das populaçôes de cianobactérias no reservatório da Pampulha (Minas Gerais) em duas escalas temporais (sazonal e diurna). Dissertação de Mestrado, Universidade Federal de Minas Gerais, Belo Horizonte, 112p. 1997.

GORAYEB, A. 2004. Análise geoambiental e dos impactos na bacia hidrográfica do rio Curu, Ceará, Brasil. 2004. Tese (Mestrado em Geografia). Universidade Estadual do Ceará, Fortaleza, 155 p. 2004.

IBGE. Pesquisa Nacional de Saneamento Básico. 2000. Disponível em: <http.://www.ibge.gov. $\mathrm{br} /$ cidadesat/ topwindow. htm?0.>. Acesso em 15/02/2005.

IBGE. Censo Populacional. 2000. Disponível em: <http.://www.ibge.gov.br>. Acesso em: $10 / 02 / 2005$.

JACOMINE. P. K. T. Levantamento exploratório reconhecimento de solos do Estado do Ceará. Recife: DDP, Convêncio MA/DNPEA/Sudene/DRN e MA/CONTAP/USAID/ETA. Boletim Técnico, 28. Série Pedagógica, 16, 1973.

JORGENSEN, S. E. \& VOLLENWEIDER, R. A. Princípios para o gerenciamento de lagos. São Carlos: ILEC, IIE, UNEP, 2000.

KOZLOWSKY-SUZUKI, B. \& BOZELLI, R. L. Experimental evidence of the effect of nutrient enrichment on the zooplankton in a Brazilian coastal lagoon. Braz. J. Biol., v. 62, p. 835-846. 2002.

LUCENA, R. P.; ROSA, M. F.; \& FIGUEIRÊDO, M. C. B. Os indicadores de saneamento $e$ a qualidade de vida na bacia hidrográfica do Curu, Ceará, Brasil. In: IV SIMPÓSIO INTERNACIONAL DE QUALIDADE AMBIENTAL, Porto Alegre.Editoração Eletrônica - Deseño Programação Visual, 2004. p. 32. 2004.

MALCZEWSKI, J. GIS and Multicriteria Decision Analysis. John Wiley \& Sons, 1999.

MASSON, S., PINEL-ALLOUL, B. \& SMITH, V. H. Total phosphorus-chlorophyll a size fractions relationships in southern Quebec lakes. Limnol. Oceanogr., v. 45, p. 732-740. 2000.

MATSUMURA-TUNDISI, T. Diversidade de zooplâncton em represas do Brasil, pp. 39-54. In: R. Henry (ed.), Ecologia de reservatórios: estrutura, função e aspectos sociais. Fundibio: Fapesp, São Paulo, 1999, 800p.

McCAULEY, E. \& KALFF, J. Empirical relationships between phytoplankton and zooplankton biomass in lakes. Can. J. Fish Aquat. Sci., v. 38, p. 458-463. 1981.

MESCHIATTI, A. J. \& ARCIFA, M. S. Early stages of fish and the relationships with zooplankton in a tropical Brazilian reservoir: lake Monte Alegre. Braz. J. Biol., v. 62, n. 1, p. 41-50. 2002.
METZGER, M. J.et al. The vulnerability of ecosystem services to land use change. Agriculture, Ecosystems and Environment, 2006.

NASA. SRTM - Shuttle Radar Topography Mission. 2000. Disponível em <www2.jpl.nasa. gov/srtm>. Acesso em: 11/01/2006.

OLIVERA, F; MAIDMENT, D. R. GIS Tools for HMS Modeling Support. In: 19th ANNUAL ESRI INTERNATIONAL USER CONFERENCE. Julho 26-30, California, 1999. Disponível em <http://ceprofs.tanu.edu/folivera/uttexas/esri99/ p801.htm. Acesso em: 08/09/2004.

PINTO-COELHO, R. M. \& ARAÚJO, M. A R. Efeitos da remoção de macrófitas sobre a disponibilidade de nitrato e amônia e o zooplancton de um reservatório eutrófico raso. In: VIII Seminário Regional de Ecologia. PPRN UFSCAR, v. 8, p. 1217-1223. 1997.

PINTO-COELHO, R. M. Effects of eutrophication on seasonal patterns of mesozooplankton. In: A TROPICAL RESERVOIR: A FOUR YEARS STUDY IN PAMPULHA LAKE, BRAZIL. Freshwat. Biol., v. 40, p. 159-174. 1998.

PINTO-COELHO, R. M. \& GRECO, M. K. The contribution of water hyacinth (Eichhornia crassipes) and zooplankton to the internal cycling of phosphorus in the eutrophic Pampulha reservoir, Brazil. Hydrobiologia, v. 411, p. 115-127. 1999.

PINTO-COELHO, R. M. et al. The nutritional status of zooplankton in a tropical reservoir: food quality and community structure. Braz. J. Biol., v. 65 , n. 2, p. 1-13.2005.

PROENÇA, C. E. M. Impactos ambientais da piscicultura em tanques-redes nos reservatórios da união. Disponível em: $<$ www.aquaculturagoiana. com.br>. Acesso em : 11/04/2006.

ROSS, J. L. S. Análise empirica da fragilidade ambiental dos ambientes naturais e antropizados. In: Revista do Departamento de Geografia (USP). (6). p. 63-74. 1994

ROSS, J. L. S. Geomorfologia: ambiente e planejamento. São Paulo: Contexto, 2005.

SAMPAIO, E. V. et al. Composition and abundance of zooplankton in the limnetic zone of seven reservoirs of the Paranapanema river, Brazil. J. Biol., v. 62, p. 525-545. 2002.

SENDACZ, S. \& KUBO, E. Zooplancton de reservatórios do Alto do Tietê, Estado de São Paulo, pp. 509-530. In: R. Henry (ed.), Ecologia de reservatórios: estrutura, função e aspectos sociais. Fundibio: Fapesp, São Paulo, 800 p. 1999.

SCHAFER, A. Fundamentos de Ecologia e Biogeografia das Aguas Continentais. GTZ/UFRGS, 1985

SOUZA. M. J. N. Diagnóstico geoambiental da bacia hidrográfica do rio Acaraú: relatório preliminar. Fortaleza, janeiro de 2005.

SPERLING, M. V. Introdução à qualidade das águas e ao tratamento de esgotos. Belo Horizonte: UFMG, 1995.

SPERLING, E. V. Morfologia de lagos e represas. Belo Horizonte: DESA/UFMG, 1999.

STARLING, F. L. R. M. Comparative study of the zooplankton composition of six lacustrine ecosystems In: Central Brazil during the dry season. Rev. Bras. Biol., v. 60, p. 101-111. 2000. 
STRASKRABA, M. Retetion time as a key variable of reservoir limnology. In: Theoretical reservoir ecology and its applications. Ed. Tundisi, J. G. e Straskraba. São Carlos: International Institute of Ecology, 1999.

VOLLENWEIDER, R. A. Advances in defining critical loading levels for phosphorus in lake eutrophication. Mem. Ist. Ital. Idrobiol, v. 33, p. 53-83. 1976.

Endereço para correspondência:

Maria Cléa Brito de Figueirêdo

Embrapa Agroindústria Tropical

Rua Dra Sara Mesquita, 2270

Pici

605 I I- I I0 Fortaleza - CE - Brasil

Tel: (85) 3299-1846

Fax: (85) 3299-1803

E-mail: clea@cnpat.embrapa.br. 